\title{
Molecular composition of fresh and aged secondary organic aerosol from a mixture of biogenic volatile compounds: a high-resolution mass spectrometry study
}

\author{
I. Kourtchev ${ }^{1}$, J.-F. Doussin ${ }^{2}$, C. Giorio ${ }^{1,3}$, B. Mahon ${ }^{1}$, E. M. Wilson ${ }^{4}$, N. Maurin ${ }^{2}$, E. Pangui ${ }^{2}$, D. S. Venables ${ }^{4}$, \\ J. C. Wenger ${ }^{4}$, and M. Kalberer ${ }^{1}$ \\ ${ }^{1}$ Department of Chemistry, University of Cambridge, Cambridge, CB2 1EW, United Kingdom \\ ${ }^{2}$ LISA, Universités Paris-Est-Créteil et Paris Diderot, CNRS UMR 7583, 61 Avenue du Général de Gaulle, \\ 94010, Créteil, France \\ ${ }^{3}$ National Centre for Atmospheric Science, School of Geography, Earth and Environmental Sciences, Division of \\ Environmental Health and Risk Management, University of Birmingham, Edgbaston, Birmingham B15 2TT, United Kingdom \\ ${ }^{4}$ Department of Chemistry and Environmental Research Institute, University College Cork, Cork, Ireland
}

Correspondence to: I. Kourtchev (ink22@cam.ac.uk) and M. Kalberer (mk594@cam.ac.uk)

Received: 6 February 2015 - Published in Atmos. Chem. Phys. Discuss.: 25 February 2015

Revised: 26 April 2015 - Accepted: 30 April 2015 - Published: 26 May 2015

\begin{abstract}
Field observations over the past decade indicate that a significant fraction of organic aerosol in remote areas may contain highly oxidized molecules. Aerosol processing or further oxidation (aging) of organic aerosol has been suggested to be responsible for their formation through heterogeneous reaction with oxidants and multigenerational oxidation of vapours by $\mathrm{OH}$ radicals. In this study we investigated the influence of several aging processes on the molecular composition of secondary organic aerosols (SOA) using direct infusion and liquid chromatography high-resolution mass spectrometry. SOA was formed in simulation chamber experiments from ozonolysis of a mixture of four biogenic volatile organic compounds (BVOC): $\alpha$-pinene, $\beta$-pinene, $\Delta_{3}$-carene and isoprene. The SOA was subsequently aged under three different sets of conditions: in the dark in the presence of residual ozone, with UV irradiation and $\mathrm{OH}$ radicals, and using UV light only. Among all studied conditions, only $\mathrm{OH}$ radical-initiated aging was found to influence the molecular composition of the aerosol and showed an increase in carbon oxidation state $\left(\mathrm{OS}_{\mathrm{C}}\right)$ and elemental $\mathrm{O} / \mathrm{C}$ ratios of the SOA components. None of the aging processes produced an observable effect on the oligomers formed from ozonolysis of the BVOC mixture, which were found to be equally abundant in both "fresh" and "aged" SOA. Additional experiments using $\alpha$-pinene as the sole precursor demonstrated
\end{abstract}

that oligomers are an important group of compounds in SOA produced from both ozonolysis and $\mathrm{OH}$ radical-initiated oxidation processes; however, a completely different set of oligomers is formed under these two oxidation regimes. SOA from the $\mathrm{OH}$-initiated oxidation of $\alpha$-pinene had a significantly higher overall $\mathrm{OS}_{\mathrm{C}}$ and $\mathrm{O} / \mathrm{C}$ compared to that from pure ozonolysis experiments confirming that the $\mathrm{OH}$ radical reaction is more likely to be responsible for the occurrence of highly oxidized species in ambient biogenic SOA.

\section{Introduction}

Biogenic volatile organic compounds (BVOCs) play an important role in atmospheric chemistry and give rise to secondary organic aerosols (SOA) that affect climate and air quality (Kanakidou et al., 2005; Hallquist et al., 2009). Although a substantial fraction (20-90\%) of atmospheric fine particulate matter is comprised of organic compounds (Jimenez et al., 2009), its molecular composition remains poorly understood. The limited knowledge of aerosol composition ultimately restricts our understanding of the most relevant particle sources.

Laboratory chamber experiments have been performed for decades in an attempt to mimic atmospheric SOA formation. 
However, it is still unclear how close the aerosol particles generated in laboratory experiments resemble atmospheric SOA with respect to their detailed chemical composition. Field observations over the past decade indicate that a significant fraction of organic aerosol in remote areas may contain highly oxidized molecules (Chen et al., 2009; Kroll et al., 2011). In contrast, laboratory-generated SOA is oxidized to a much lesser extent, suggesting that the conditions in smog chamber experiments are not optimal for mimicking aging in the atmosphere (Donahue et al., 2012). One likely reason for this difference in composition is that the reaction times in chamber experiments are significantly shorter than the lifetime of organic aerosol in the real atmosphere (e.g. Shilling et al., 2009). Another explanation for the difference is that typical smog chamber experiments are performed with only one or two SOA precursors and are often limited to one oxidant (e.g. $\mathrm{O}_{3}$ or $\mathrm{OH}$ radicals).

It has been suggested that aerosol processing or further oxidation (aging) of OA could be responsible for formation of highly oxidized OA components through heterogeneous reaction with oxidants and multigenerational oxidation of vapours by OH radicals (Henry and Donahue, 2012). Several $\mathrm{OH}$ radical initiated aging experiments have been performed with $\alpha$-pinene, its oxidation products (Donahue et al., 2012; Müller et al., 2012; Denjean et al., 2015; Romonosky et al., 2015 ) and a mixture with limonene and $p$-xylene (Emanuelsson et al., 2013; Flores et al., 2014). It was found that hydroxyl radical aging significantly increases the concentration of first-generation BSOA components as determined from both $\mathrm{O} / \mathrm{C}$ elemental ratios and individual marker compounds. In addition, atmospheric aging was proposed to have a role in the formation of high molecular weight compounds or oligomers (Kalberer et al., 2004) through condensed (Rudich et al., 2007) or aqueous (Renard et al., 2015) phase chemistry.

The influence of aqueous photochemical processing on the average molecular composition of SOA produced from several biogenic and anthropogenic precursors has also been recently investigated (Romonosky et al., 2015). A reduction of the average number of atoms in the SOA molecular formulae was observed after photolysis - however, without a significant effect on the overall $\mathrm{O} / \mathrm{C}$ and $\mathrm{H} / \mathrm{C}$ ratios. In another study, condensed-phase photochemistry in the near-ultraviolet $(\lambda>300 \mathrm{~nm})$ was shown to induce significant changes in SOA particle size and composition (Epstein et al., 2014).

The influence of aging on oligomer formation is generally inferred from analysis of the elemental $\mathrm{O} / \mathrm{C}$ and $\mathrm{H} / \mathrm{C}$ ratios. However, other chemical processes such as carboxylation and carbonylization are also known to affect the elemental ratios. Additionally, the effects of aging on oligomerization have been assessed by monitoring the concentration of 2-5 dimers that could be identified by liquid chromatography mass spectrometry (LC/MS) (Emanuelsson et al., 2013). Other techniques such as high-resolution mass spectrometry
(HRMS) often identify hundreds of oligomeric compounds (Tolocka et al., 2004; Kalberer et al., 2004; Reinhardt et al., 2007; Hall and Johnston, 2011; Putman et al., 2012; Kundu et al., 2012; Kourtchev et al., 2014), which raises the question of whether the small number of dimers that can be quantified with LC/MS reliably represent the entire oligomer content in SOA.

The objectives of this work were to examine the influence of several aging conditions on the molecular composition of biogenic SOA. SOA formed from ozonolysis of a BVOC mixture was exposed to (i) residual ozone in the dark, (ii) $\mathrm{OH}$ radicals and UV light, and (iii) UV light only. The BVOC mixture contained the four most abundant compounds (i.e. $\alpha$ and $\beta$-pinene, $\Delta_{3}$-carene, and isoprene) detected at a remote boreal forest site Hyytiälä, Finland (Hakola et al., 2003; Aaltonen et al., 2011; Bäck et al., 2012; Kourtchev et al., 2014). The aged SOA was characterized using direct infusion and LC HR-MS which allows detection of thousands of individual SOA constituents at once providing their elemental formulae from accurate mass measurements (Nizkorodov et al., 2011).

\section{Methods}

All aerosol aging experiments were performed in the CESAM chamber in Paris. Supplementary experiments on the ozonolysis and OH-initiated oxidation of $\alpha$-pinene were conducted in the CRAC chamber in Cork.

\subsection{CESAM experiments}

Aerosol aging experiments were carried out in the CESAM chamber (French acronym for Experimental Multiphasic Atmospheric Simulation Chamber). A detailed description of the chamber is provided elsewhere (Wang et al., 2011). Briefly, the chamber is a $4.2 \mathrm{~m}^{3}$ stainless steel vessel, operated at $296 \pm 2 \mathrm{~K}$ using synthetic air at $1 \mathrm{bar}$ atmospheric pressure. The solar irradiation is mimicked using xenon arc lamps (4kW, XPO $4000 \mathrm{~W} / \mathrm{HS}$, OSRAM) fitted with $8 \mathrm{~mm}$ Pyrex filters that provide an emission spectrum closely resembling that at the Earth's surface near the equator over the wavelength range $290-700 \mathrm{~nm}$ (Wang et al., 2011). For these experiments, the corresponding $\mathrm{NO}_{2}$ photolysis frequency was $\mathrm{J}_{\mathrm{NO}_{2}}=(2.5 \pm 0.2) \times 10^{-3} \mathrm{~s}^{-1}$. The experimental conditions are outlined in Table 1 . The experiments were performed at a relative humidity (RH) of $2-9 \%$. Neutral seed particles of ammonium sulfate were generated from $3 \mathrm{mM}\left(\mathrm{NH}_{4}\right)_{2} \mathrm{SO}_{4}$ (Sigma-Aldrich, $99.99 \%$ ) solution using an atomiser (TSI ${ }^{\circledR}$ model 3075$)$ and dried using a diffusion dryer (TSI ${ }^{\circledR}$, model 3062) before introduction into the chamber. BVOCs (i.e. $\alpha$-pinene, $\beta$-pinene, $\Delta_{3}$-carene and isoprene) were introduced into the chamber by flowing purified air over known amounts of the compounds in a gently heated Pyrex impinger. While the total concentrations of 
Table 1. Experimental conditions at CESAM chamber.

\begin{tabular}{llrrr}
\hline $\begin{array}{l}\text { SOA Exposure } \\
\text { type }\end{array}$ & Experiment & $\begin{array}{r}\mathrm{O}_{3} \text { conc. } \\
{[\mathrm{ppb}]}\end{array}$ & $\mathrm{RH}[\%]$ & $\begin{array}{r}\text { SOA exposure } \\
\text { time [h] }\end{array}$ \\
\hline Dark aging & Replicate 1 & 450 & $3-6$ & 9 \\
& Replicate 2 & 450 & $2.7-4.9$ & 9 \\
\hline OH radical and & Replicate 1 & 300 & $4.9-8.2$ & 8 \\
UV exposure & Replicate 2 & 300 & $4-7.2$ & 8 \\
\hline UV exposure & Replicate 1 & 300 & $3-9$ & 8 \\
& Replicate 2 & 300 & $3.5-8$ & 8 \\
\hline
\end{tabular}

BVOC mixture concentration in all experiments was about $150 \mathrm{ppb}$ ( $60 \mathrm{ppb}$ of $\alpha$-pinene, $45 \mathrm{ppb}$ of $\Delta_{3}$-carene, $30 \mathrm{ppb}$ of $\beta$-pinene and $15 \mathrm{ppb}$ of isoprene). $\left(\mathrm{NH}_{4}\right)_{2} \mathrm{SO}_{4}$ aerosol seed

concentration was about $5 \mu \mathrm{g} \mathrm{m}^{-3}$ in all experiments. Listed conditions are for the initial

formation of the SOA and not for the subsequent aging reaction.

the BVOC mixture used in these chamber experiments exceeded (up to 10 times, depending on the season) those observed at the Finnish site, their molar ratios were kept very close to the reported values (i.e. $\alpha$-pinene, $0.4 ; \Delta_{3}$-carene, 0.3 ; $\beta$-pinene, 0.2 ; and isoprene, 0.1 ). The total VOC mixture concentration was about $150 \mathrm{ppb}$ for all CESAM experiments. The precursor hydrocarbons concentrations and their decay were measured using in situ FTIR spectroscopy. After injecting the BVOC mixture and allowing it to stabilize for 5-10 min, ozone was introduced into the chamber over a period of $10-15 \mathrm{~s}$ from an electric discharge generator. Infrared absorbing species such as SOA precursors and their oxidation products were measured during the reactions using multi-path in situ Fourier transform infrared (FTIR) spectrometry (Bruker GmbH, Ettlingen, Germany) with an optical pathlength of $192 \mathrm{~m}$. The concentration of $\mathrm{NO}_{x}$ throughout the experiments was below the detection limit.

Particle size distributions (from 19 to $980 \mathrm{~nm}$ in diameter) were measured with a TSI ${ }^{\circledR} 3080$ scanning mobility particle sizer (SMPS) and a TSI ${ }^{\circledR} 3010$ condensation particle counter operating with $0.2 \mathrm{~L} \mathrm{~min}^{-1}$ sample flow and $2.0 \mathrm{~L} \mathrm{~min}^{-1}$ sheath flow. For the SOA mass concentration, the density of the organic material was assumed to be $1.0 \mathrm{~g} \mathrm{~cm}^{-3}$.

While this choice of density affects the estimated mass of collected SOA, the major conclusions of this work are not sensitive to the actual value of SOA density.

SOA samples were collected in three stages: (a) after reaching the maximum particle concentration (as measured by SMPS) during the dark ozonolysis reaction of the VOC mixture; (b) after $3 \mathrm{~h}$ of exposure of the $\mathrm{SOA}$ particles to $\mathrm{OH}$ radicals and/or UV radiation and (c) after 8-9 $\mathrm{h}$ of exposure of the SOA particles to $\mathrm{OH}$ radicals and/or UV radiation.

$\mathrm{OH}$ radicals for the aging experiments were produced by photolysis of $\mathrm{H}_{2} \mathrm{O}_{2}\left(60 \% \mathrm{w} / v\right.$, Fisher Scientific). $\mathrm{H}_{2} \mathrm{O}_{2}$ (produced by evaporation of $60 \% \mathrm{w} / v$ solution, Fisher Scientific) was continuously injected into the smog chamber approximately $1 \mathrm{~h}$ after reaching the maximum SOA concentra- tion (mean maximum concentration $122 \pm 21 \mu \mathrm{g} \mathrm{m}^{-3}, n=6$ ) produced from the dark ozonolysis reaction.

For the two $\mathrm{OH}$-induced aging experiments, the $\mathrm{OH}$ concentration was estimated using the Master Chemical Mechanism (Jenkin et al., 1997, 2015; Saunders et al., 2003), MCM v3.3, via website: http://mcm.leeds.ac.uk/MCM. The MCM contains detailed chemical mechanisms for isoprene, $\alpha$-pinene and $\beta$-pinene, but not for $\Delta_{3}$-carene. As a result, a module describing the chemistry of $\Delta_{3}$-carene was constructed using the well-characterized reactions of the structurally similar compound $\alpha$-pinene as a basis. Following the work of Atkinson et al. $(1986,1990)$, the rate constants used for the reaction of ozone and $\mathrm{OH}$ with $\Delta_{3}$-carene were $0.44 \times$ $k\left(\mathrm{O}_{3}+\alpha\right.$-pinene $)$ and $0.55 \times k(\mathrm{OH}+\alpha$-pinene $)$ respectively. The concentration of $\mathrm{H}_{2} \mathrm{O}_{2}$, determined from FTIR measurements, was constrained in the model, as well as the temperature, the relative humidity and the dilution flow induced by sampling. The initial concentration of VOCs and ozone used in the MCM were measured at the start of the ozonolysis reaction. A value of $J\left(\mathrm{H}_{2} \mathrm{O}_{2}\right)=(3.2 \pm 0.4) \times 10^{-6} \mathrm{~s}^{-1}$ was used, based on the measured light intensity distribution in the CESAM chamber (Wang et al., 2011). Using these inputs, the overall $\mathrm{OH}$ exposure was determined to be $1.7 \times 10^{7}$ and $1.3 \times 10^{7}$ molecule $\mathrm{cm}^{-3} \mathrm{~h}$ in the two experiments, which is comparable to similar studies in the literature (Eddingsaas et al., 2012; Qi et al., 2012; Henry and Donahue, 2012).

\subsection{CRAC experiments}

Supplementary experiments on the ozonolysis and $\mathrm{OH}-$ initiated oxidation of $\alpha$-pinene were performed at the Centre for Research into Atmospheric Chemistry (CRAC) simulation chamber in Cork (Thüner et al., 2004, Kourtchev et al., 2014). The chamber is a cylinder made of fluorine-ethenepropene (FEP) Teflon ${ }^{\circledR}$ foil with a volume of $3.91 \mathrm{~m}^{3}$. It was operated at $296 \pm 2 \mathrm{~K}$ using purified air at $0.1-1 \mathrm{mbar}$ above atmospheric pressure. The experiments were performed at $55 \pm 2 \%$ relative humidity produced from bubbling purified air through heated water. The humidity and temperature 
were measured using a dew point meter $\left(\right.$ DRYCAP $^{\circledR}$ DM70 Vaisala). Between experiments the chamber was cleaned by introducing about $1 \mathrm{ppm}$ of ozone into the chamber and flushing with purified air at a flow rate of $0.15 \mathrm{~m}^{3} \mathrm{~min}^{-1}$. Aerosol seed particles produced from atomising $\left(\mathrm{NH}_{4}\right)_{2} \mathrm{SO}_{4}$ were neutralized by a Krypton- 85 (Kr-85) charge neutralizer before introduction to the chamber with a concentration of approximately $5 \mu \mathrm{g} \mathrm{m}^{-3} . \alpha$-pinene was introduced into the chamber in the similar manner as described above for the CESAM experiments. $\mathrm{OH}$ radicals were generated from the photolysis of hydrogen peroxide $\left(\mathrm{H}_{2} \mathrm{O}_{2}\right)$, which was added to the chamber by bubbling purified air into a slightly heated $\left(\sim 40-50{ }^{\circ} \mathrm{C}\right)$ solution of $50 \% \mathrm{H}_{2} \mathrm{O}_{2}$. After the introduction of all reactants, the mixture was allowed to mix for $10 \mathrm{~min}$ before turning on 12 Philips TL12 (40 W) lamps with $\lambda_{\max }=310 \mathrm{~nm}$ to initiate photolysis of the $\mathrm{OH}$ radical precursor. Based on the measured distribution of light intensity in the chamber (Healy et al., 2012), the steadystate concentration of $\mathrm{OH}$ radicals was estimated to be ca. $4 \times 10^{6}$ molecule $\mathrm{cm}^{-3}$. For the ozonolysis-only experiments, $\sim 2$ ppm of ozone was introduced into the chamber over a period of 1-2 min from an electric discharge generator. Cyclohexane ( $\sim 40 \mathrm{ppm}$, Sigma, $>99 \%$ purity) was used as an $\mathrm{OH}$ scavenger in the ozonolysis-only experiments. The concentration of $\mathrm{NO}_{x}$ was monitored using a standard $\mathrm{NO}_{x}$ analyzer (Thermo Model 42i) was found to increase gradually from 0 to around $25 \mathrm{ppb}$ during the course of the reactions, due to $\mathrm{NO}_{x}$ offgassing from the Teflon walls (Carter et al., 2005; Rohrer et al., 2005).

\subsection{Aerosol sample collection}

Total aerosol mass was collected on prebaked (at $650^{\circ} \mathrm{C}$ ) quartz fibre filters (47 mm diameter, Tissuquartz 2500 QATUP, Pall Life Sciences) using a stainless steel $47 \mathrm{~mm}$ inline filter holder (Pall Life Sciences). The gas phase species were removed using a custom-built $1 \mathrm{~m}$ long denuder packed with activated charcoal (NORIT ${ }^{\circledR}$ ROW 0.8 SUPRA, SigmaAldrich). The denuder was purged using clean air for at least $12 \mathrm{~h}$ prior to experiments. The sampling was performed at flow rate of $18-30 \mathrm{~L} \mathrm{~min}^{-1}$ for $1-2 \mathrm{~h}$ depending on the SOA concentration in the chamber. To maintain constant pressure in the CESAM chamber, synthetic air was added during aerosol sample collection. A series of chamber blanks were collected by drawing clean air containing aerosol seed that was exposed to ozone, $\mathrm{H}_{2} \mathrm{O}_{2}$ and $\mathrm{UV}$ irradiation from the smog chamber. Aerosol samples were immediately placed into prewashed glass vials and stored in the freezer until analysis.

\subsection{Aerosol analysis}

Depending on the aerosol loading of the filter samples, which varied between 50 and $150 \mu \mathrm{g}$ per filter, a part of the quartz fibre filter $\left(5-20 \mathrm{~cm}^{2}\right)$ was extracted three times with $5 \mathrm{~mL}$ of methanol (Optima TM grade, Fisher Scientific) under ultrasonic agitation in slurry ice for $30 \mathrm{~min}$. The extracts were combined, filtered through a Teflon filter $(0.2 \mu \mathrm{m}$, ISODiscTM Supelco), and reduced by volume to approximately $50-200 \mu \mathrm{L}$ under a gentle stream of nitrogen. The sample was split into two parts for direct infusion and LC/MS analyzes. The concentration of SOA extracts for direct infusion analysis was adjusted to the same level of approximately $0.25 \mu \mathrm{g}$ organic carbon $\mu \mathrm{L}^{-1}$. The LC/MS portion was further evaporated to $20 \mu \mathrm{L}$ and diluted by $0.1 \%$ aqueous solution of formic acid to $100 \mu \mathrm{L}$.

Bateman et al. (2008) observed facile formation of hemiacetals in reaction of SOA carbonyls with methanol and slow formation of esters in reaction of SOA carboxylic acids with methanol. Although the detailed evaluation of the differences between the two solvents was not performed in this study, a preliminary comparison of the mass spectra for both methanol and acetonitrile extracts of several boreal forest samples did not show any major differences that could be attributed to methylesters of carboxylic acids.

The final extracts were analyzed as described in Kourtchev et al. (2013) using a high-resolution LTQ Orbitrap Velos mass spectrometer (Thermo Fisher, Bremen, Germany) equipped with electrospray ionization (ESI) and a TriVersa Nanomate robotic nanoflow chip-based ESI (Advion Biosciences, Ithaca NY, USA) source.

The Orbitrap MS was calibrated using an Ultramark 1621 solution (Sigma-Aldrich, UK). The mass accuracy of the instrument was routinely checked before the analysis and was below $1 \mathrm{ppm}$. The instrument mass resolution was 100000 at $\mathrm{m} / \mathrm{z} 400$. A mixture of camphor sulfonic acid $\left(20 \mathrm{ng} \mu \mathrm{L}^{-1}\right)$, glutaric acid (30 ng $\left.\mu \mathrm{L}^{-1}\right)$, and cis-pinonic acid (30 $\mathrm{ng} \mu \mathrm{L}^{-1}$ ) in methanol and Ultramark 1621 solution were used to optimize the ion transmission settings.

The direct infusion nanoESI parameters were as follows: the ionization voltage and back pressure were set at $-1.4 \mathrm{kV}$ and $0.8 \mathrm{psi}$, respectively. The inlet temperature was $200^{\circ} \mathrm{C}$. The sample flow rate was approximately $200-300 \mathrm{~nL} \mathrm{~min}^{-1}$. The negative ionization mass spectra were collected in three replicates at ranges $m / z, 100-650$ and $m / z, 150-900$ and processed using Xcalibur 2.1 software (Thermo Scientific).

Examples of the spectra obtained for both analytical and smog chamber replicates are shown in Figs. S1 and S2 (in the Supplement). The average percentage of common peaks between analytical replicates was $78 \%$ (range of 70-87\%), which agrees with literature reports for similar data analysis (Sleighter et al., 2012). The percentage of common peaks between smog chamber replicates varied between 82 and $90 \%$. A largest fraction of non-common ions in the replicates had $\mathrm{RI}<0.05 \%$.

LC-MS ESI parameters were as follows: spray voltage $-3.6 \mathrm{kV}$; capillary temperature $300^{\circ} \mathrm{C}$; sheath gas flow 10 arbitrary units, auxiliary gas flow 10 ; sweep gas flow rate 5; S-lens RF level $55 \%$. The sample extracts were injected at a flow rate of $200 \mu \mathrm{L} \mathrm{min}{ }^{-1}$. LC/(-)ESI-MS analysis was per- 
formed using an Accela system (Thermo Scientific, San Jose, USA) coupled with LTQ Orbitrap Velos MS and a T3 Atlantis C18 column $(3 \mu \mathrm{m} ; 2.1 \times 150 \mathrm{~mm}$; Waters, Milford, USA). The mobile phases consisted of $0.1 \%$ formic acid $(v / v)(\mathrm{A})$ and methanol (B). The applied gradient was as follows: $0-3 \min 3 \% \mathrm{~B}, 3-25 \mathrm{~min}$ from 3 to $50 \% \mathrm{~B}$ (linear), 25-43 min from 50 to $90 \%$ B (linear), 43-48 min from 90 to $3 \% \mathrm{~B}$ (linear), and kept for $12 \mathrm{~min}$ at $3 \% \mathrm{~B}$ (total run time $60 \mathrm{~min})$. MS spectra were collected in full scan using the lock mass for the deprotonated dimer of formic acid at $m / z 91.00368$ with the resolution of 100000 and the mass ranges of $m / z \quad 100-650$ and $m / z \quad 150-900$. On the basis of prescan information from the full scan MS, a parallel datadependent collision-induced dissociation (CID) multistage mass spectrometry $\left(\mathrm{MS}^{n}\right)(n=1,2,3$, and 4$)$ was performed on the most intense precursor ion in three scans at a resolution of 30000 .

For the majority of the identified organic species, authentic standards were not available; therefore, cis-pinonic acid, ketopinic acid and terebic acid were used as surrogates to quantify most of the acids in the samples (Kristensen et al., 2014). The identification was performed by comparing MS fragmentation patterns and chromatographic elution times reported in the literature (Yasmeen et al., 2010, 2012; Kristensen et al., 2014). The dimers were quantified using cispinonic acid as surrogate. Six-point calibration curves were constructed over two concentration ranges $0.2-50$ and 50$200 \mathrm{ng} \mu \mathrm{L}^{-1}$.

\subsection{High MS resolution data analysis}

The direct infusion data analysis was performed using procedures described in detail by Kourtchev et al. (2013). Briefly, for each sample analysis, 60-90 mass spectral scans were averaged into one mass spectrum. Molecular assignments were made using Xcalibur 2.1 software applying the following constraints ${ }^{12} \mathrm{C} \leq 100,{ }^{13} \mathrm{C} \leq 1,{ }^{1} \mathrm{H} \leq 200,{ }^{16} \mathrm{O} \leq 50,{ }^{14} \mathrm{~N} \leq 5$, ${ }^{32} \mathrm{~S} \leq 2,{ }^{34} \mathrm{~S} \leq 1$. The data filtering was performed using a Mathematica 8.0 (Wolfram Research Inc., UK) code developed in-house that employed several conservative rules and constraints used in previous studies (Kourtchev et al., 2013). In this study, only ions that appeared in all three replicates were kept for evaluation.

\section{Results and discussions}

\subsection{Direct infusion results}

Figure 1 shows direct infusion negative ionization (-) nanoESI HR mass spectra for "fresh" SOA collected after $1 \mathrm{~h}$ of dark ozonolysis reaction of the BVOC mixture and "aged" SOA collected after $8-9 \mathrm{~h}$ of aging under different atmospheric conditions (i.e. dark exposure of SOA in the presence of residual $\mathrm{O}_{3}$, exposure to $\mathrm{OH}$ radicals and $\mathrm{UV}$ light, exposure to UV light only). It should be noted that all mass spectra are blank corrected and show only ions containing carbon, hydrogen and oxygen that appeared in three analytical replicates of two repeated chamber experiments. ESI is a soft ionization technique which usually shows very little or no fragmentation. Thus, in the negative ionization mode it is expected that the detected ions correspond to the deprotonated molecules.

Irrespective of the applied atmospheric oxidation conditions, the mass spectra from all SOA samples contained distinct groups of monomers, dimers and trimers in the mass range 100-650. Similar to laboratory studies with biogenic SOA from previous studies (e.g. Tolocka et al., 2004; Hall and Johnston, 2011; Putman et al., 2012; Kundu et al., 2012), the ion intensities in the oligomeric region $(\mathrm{m} / z>280)$ were very high (up to $25 \%$ relative intensities, see Fig. 1) and exhibited a bell shape distribution. This is in contrast to the HRMS analysis of ambient organic aerosol from various sampling locations (e.g. Wozniak et al., 2008; Kourtchev et al., 2013, 2014), where mass spectra generally have a unimodal distribution with relatively low ion intensities in the high mass range.

None of the aging reactions studied here caused any visible influence on the ion intensity distributions except for an ion at $m / z$ 357.15509. Moreover, several of the oligomers were not affected by the $8-9 \mathrm{~h} \mathrm{OH}$ radical/UV light and UV light-only exposures. This clearly shows that even prolonged exposure to $\mathrm{OH}$ radicals and UV light does not cause decomposition of oligomers formed under the employed ozonolysis conditions, thus indicating their stability once they are formed in the atmosphere. This is in contrast to results reported for aqueous photochemical processing of SOA from various biogenic ( $\alpha$-pinene, $\beta$-pinene, D-limonene, $\alpha$ humulene) and anthropogenic (1,3,5-trimethylbenzene and guaiacol) precursors (Romonosky et al., 2015). In this latter study, a reduction of the average number of atoms in the SOA molecular formulae was observed after photolysis suggesting that the presence of water plays an important role in the aging processes of SOA. It has also been shown that relative humidity can affect the viscosity of SOA particles and potentially affect heterogeneous oxidation kinetics (e.g. Zhou et al., 2013).

In all experiments, the mass spectra were dominated by the ions at $m / z 185.08167$ and $m / z 357.15509$ in the monomeric and dimeric regions respectively. As confirmed by LC/MS analysis (discussed below), the ion at $m / z 185.08167$ corresponds to at least three different oxidation products with the same molecular formula $\left(\mathrm{C}_{9} \mathrm{H}_{14} \mathrm{O}_{4}\right)$ which are formed from $\alpha$-, $\beta$-pinene, and $\Delta_{3}$-carene, the major compounds in the studied BVOC mixture (Table S1). They include cis-pinic acid, homoterpenylic acid, and cis-caric acid. A dimer at $m / z 357.15509$ was previously identified as pinyl-diaterpinyl ester MW 358 in the SOA from ozonolysis of $\alpha$-pinene (Müller et al., 2008, 2009; Camredon et al., 2010; Yasmeen et al., 2010; Gao et al., 2010; Kristensen et al., 2013). Since pinyl-diaterpinyl ester MW 358 was not observed in the 


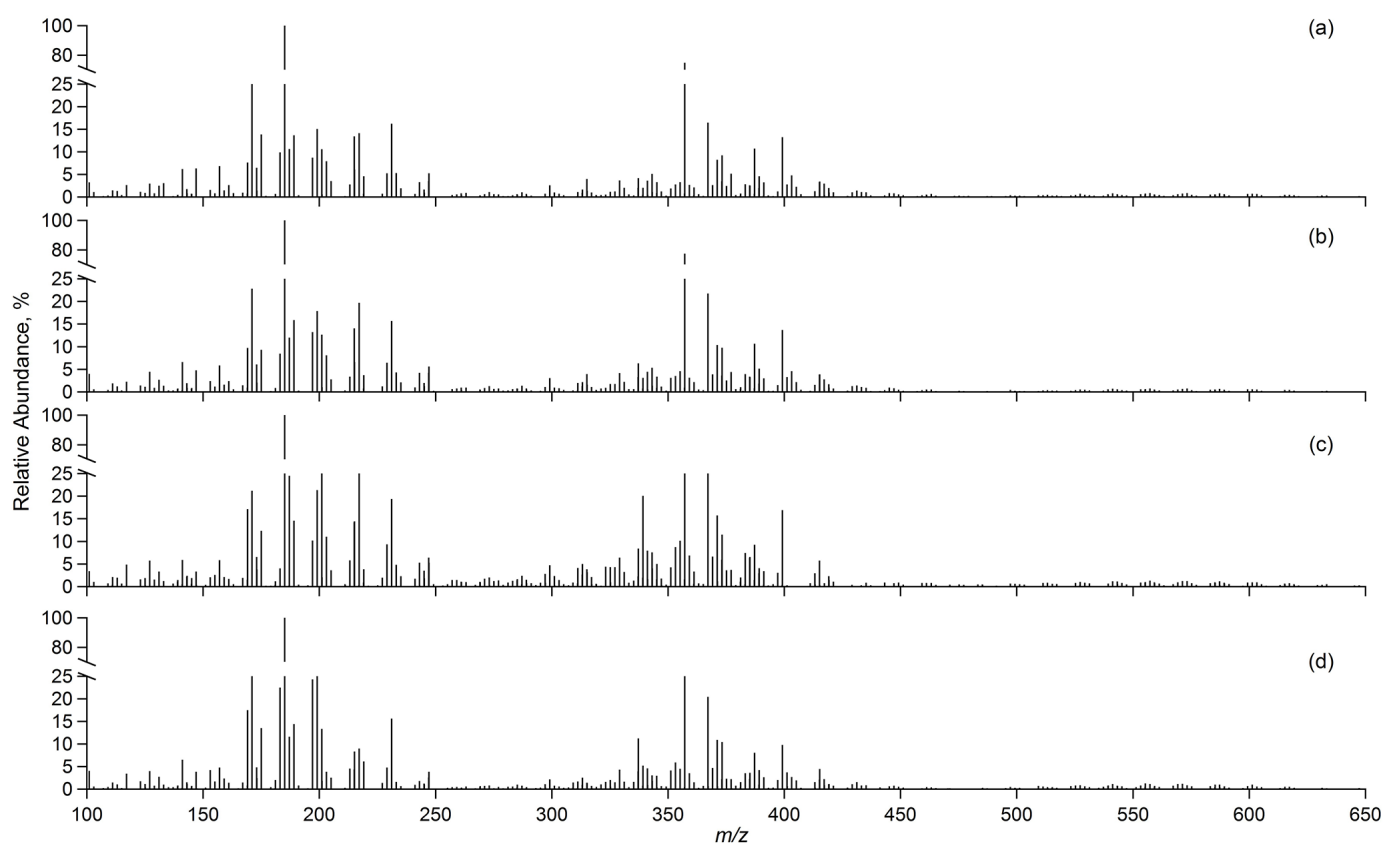

Figure 1. Direct infusion (-) nanoESI HRMS of SOA from dark ozonolysis of BVOC mixture: (a) fresh aerosol, (b) aged for $9 \mathrm{~h}$ in dark (with residual ozone), (c) aged for $8 \mathrm{~h}$ in the presence of $\mathrm{O}_{3}, \mathrm{H}_{2} \mathrm{O}_{2}$ and $\mathrm{UV}$ light and (d) aged for $9 \mathrm{~h}$ in the presence of $\mathrm{O}_{3}$ and $\mathrm{UV}$ light.

SOA from the $\mathrm{OH}$ radical initiated oxidation of $\alpha$-pinene, it was suggested that high molecular weight dimers are formed through gas phase reaction of the stabilized Criegee Intermediate formed from ozonolysis of the monoterpene (Kristensen et al., 2014).

In addition, the data were visualized using carbon oxidation state $\left(\mathrm{OS}_{\mathrm{C}}\right)$ plots. The $\mathrm{OS}_{\mathrm{C}}$ was introduced in aerosol science by Kroll et al. (2011) to describe the composition of a complex mixture of organics undergoing dynamic oxidation processes. It is strongly linked to aerosol volatility and thus is a useful parameter to classify SOA. While highly oxidized organics in organic aerosol have $\mathrm{OS}_{\mathrm{C}} \geq+1$, the reduced molecules have $\mathrm{OS}_{\mathrm{C}} \leq 0$. The maximum in chemical complexity is located at $\mathrm{OS}_{\mathrm{C}}=0$ (Kroll et al., 2011). Carbon oxidation state was calculated for each molecular formula identified in the mass spectra using the following equation:

$\mathrm{OS}_{\mathrm{C}}=-\sum_{i} \mathrm{OS}_{i} \frac{n_{i}}{n_{\mathrm{C}}}$

where $\mathrm{OS}_{i}$ is the oxidation state associated with element $i$, and $n_{i} / n_{\mathrm{C}}$ is the molar ratio of element $i$ to carbon (Kroll et al., 2011).

Figure 2 shows two overlaid OS $_{C}$ plots for the "fresh" and "aged" SOA from the "dark aging" experiments. Consistent with previous studies, the majority of molecules in the SOA had $\mathrm{OS}_{\mathrm{C}}$ between -1 and +1 with up to $30\left(n_{\mathrm{C}}\right)$ carbon atoms (Kroll et al., 2011, and references therein). It has been suggested that semivolatile and low-volatility oxidized organic aerosol (SV-OOA and LV-OOA) produced by multistep oxidation reactions have $\operatorname{OS}_{C}$ between -1 and +1 with

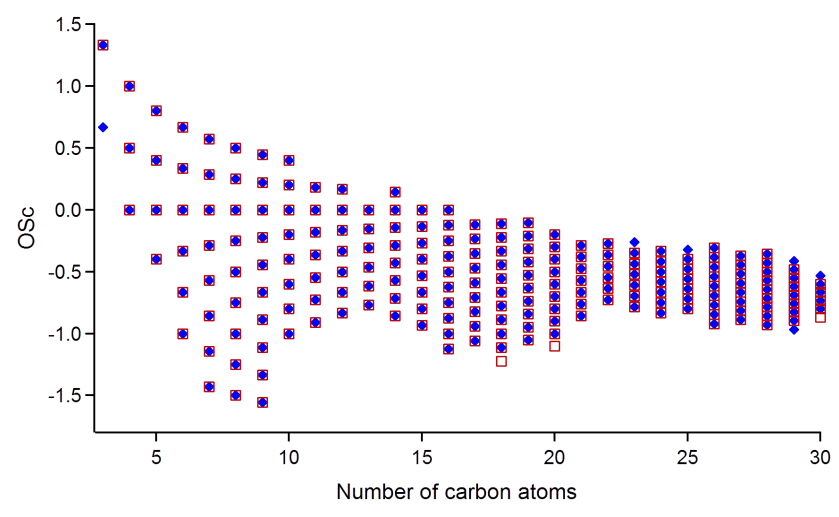

Figure 2. Carbon oxidation state of SOA from BVOC mixture from dark aging experiments with $\mathrm{O}_{3}$. Blue diamonds correspond to molecules in fresh SOA, red squares to aged SOA for $9 \mathrm{~h}$.

13 or less carbon atoms (Kroll et al., 2011). It should be noted that all SOA samples contained a cluster of molecules with $\mathrm{OS}_{\mathrm{C}}$ between -1 and -1.5 with $n_{\mathrm{C}}$ less than 10 which could possibly be associated with $\mathrm{OH}$ radical oxidation products of isoprene, which was present in the BVOC mixture. The dark ozonolysis experiments were performed without an $\mathrm{OH}$ scavenger and thus it is likely that $\mathrm{OH}$ radicals produced from the ozonolysis reactions could further react with isoprene resulting in the molecules with very low $\mathrm{OS}_{\mathrm{C}}$ state. The large cluster of molecules with 15 or more carbon atoms is likely to be associated with dimers and trimers of the BVOC oxidation products. 


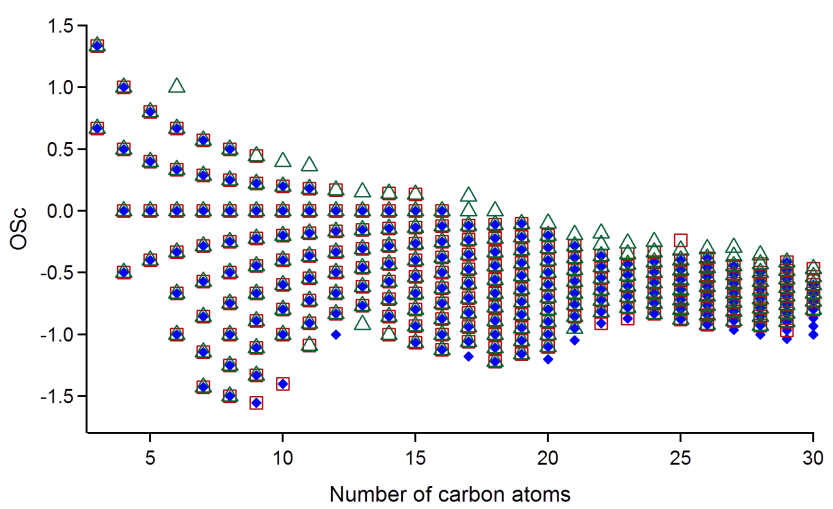

Figure 3. Carbon oxidation state of SOA from $\mathrm{OH}$-initiated aging of aerosol from ozonolysis of BVOC mixture. Blue diamonds correspond to molecules in "fresh SOA", red squares to "aged SOA" for $3 \mathrm{~h}$ and green triangles to aged SOA for $9 \mathrm{~h}$.

Figure 3 shows a carbon oxidation plot for the $\mathrm{OH}$ radical aging experiments performed in the presence of UV light. In contrast to dark aging experiments, a very small shift in the oxidation state throughout the entire mass range could be observed with aging time. This shift is not visible in the mass spectrum shown in Fig. 1c because the affected ions had very low intensities (mostly $<5 \%$ relative intensity). The observed increase in the oxidation state of the SOA components is consistent with the results obtained for the $\mathrm{OH}$ radical aging of SOA produced by dark ozonolysis reaction of $\alpha$-pinene (Donahue et al., 2012). Using an aerosol mass spectrometer (AMS), an increase of the $\mathrm{O} / \mathrm{C}$ ratio, which is another metric to describe the oxidation state of the SOA components, was observed after addition of $\mathrm{OH}$ radicals (Donahue et al., 2012).

To identify a possible reason for the small shift in $\mathrm{OS}_{\mathrm{C}}$ to the higher values during the aging reaction observed in the present study, we performed separate $\mathrm{O}_{3}$ and $\mathrm{OH}$ radical initiated oxidation experiments with $\alpha$-pinene (the major component of the BVOC mixture) in the CRAC chamber. In a previous study (Kourtchev et al., 2014) we compared molecular composition of SOA from ozonolysis of a single VOC ( $\alpha$-pinene) with that from the VOC mixture $(\alpha$ pinene, $\beta$-pinene, $\Delta_{3}$-carene and isoprene) and showed that the molecular composition of $\alpha$-pinene SOA was very similar to that from the BVOC mixture. It must be noted that the later experiments were performed at the different smog chamber (CRAC) and high $\mathrm{RH}(\sim 55 \%)$. Since an $\mathrm{OH}$ radical scavenger was used in these ozonolysis experiments, we assume that all $\mathrm{OH}$ radicals were efficiently removed from the system. SOA from both ozonolysis and $\mathrm{OH}$ radical reaction with $\alpha$-pinene contained distinguishable groups of monomers, dimers and trimers (Fig. 4). However, a clear shift to higher masses is observed in the mass spectra from the $\mathrm{OH}$ radical experiments. The presence of a large number of oligomers in the SOA from the $\mathrm{OH}$-initiated reaction

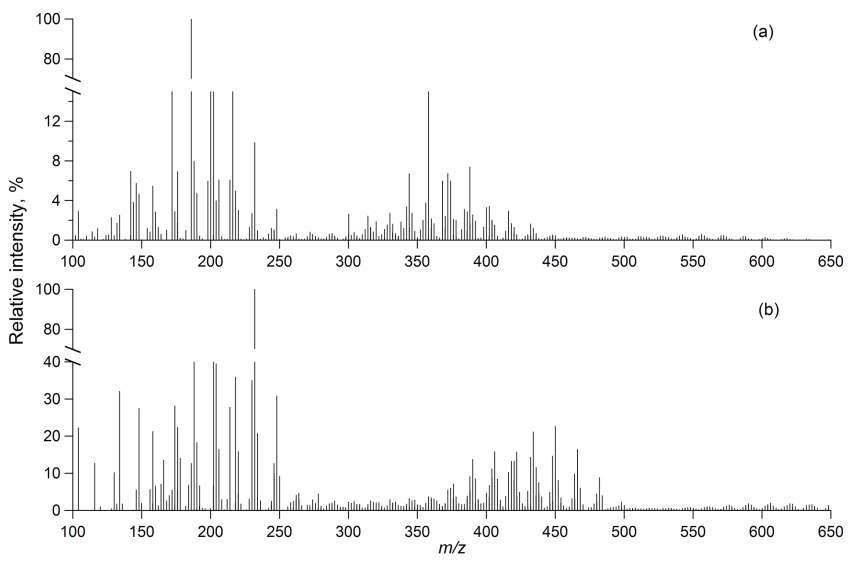

Figure 4. Direct infusion (-) nanoESI-HR mass spectra of the SOA from (a) dark ozonolysis and (b) $\mathrm{OH}$-initiated reaction with $\alpha$ pinene.

indicates that this oxidation regime also results in a significant degree of oligomerization. In-source fragmentation tests with a fragmentation voltage of up to $70 \mathrm{~V}$ showed no significant change in the number of observed oligomers in the mass spectra, thus ruling out the possibility that these oligomers are noncovalent compounds formed in the ESI source. When the fragmentation voltage was increased to $80 \mathrm{~V}$, a decrease in the intensities for both monomers and dimers was observed, confirming that detected dimers are covalent species.

The SOA from the $\mathrm{OH}$ reaction clearly shows higher $\mathrm{OS}_{\mathrm{C}}$ (Fig. 5, red squares) compared to that from the dark ozonolysis experiments (blue diamonds in Fig. 5). Moreover, it contained a very large number of LV-OOA species, which are often referred to as aged SOA (Kroll et al., 2011). As indicated in the Van Krevelen diagram (Fig. 6), where H / C ratio is plotted as a function of the $\mathrm{O} / \mathrm{C}$ ratio for each mass and corresponding formula identified in the sample (Nizkorodov et al., 2011), the SOA from the $\mathrm{OH}$-initiated reaction had substantially higher $\mathrm{O} / \mathrm{C}$ ratios than those for SOA obtained from ozonolysis. On the other hand, $\mathrm{H} / \mathrm{C}$ ratios were very similar in SOA from both reactions. This may be explained by addition of carboxylic or carbonylic groups to the backbone of the hydrocarbon structure, which generally occurs without substantial loss of hydrogen (Zhao et al., 2015).

In the UV-only aging experiments (without addition of $\mathrm{H}_{2} \mathrm{O}_{2}$ ) no visible effect on the mass spectral features of the oligomers (Fig. 1d) and $\mathrm{OS}_{\mathrm{C}}$ (not shown here) could be observed. Considering that during the UV-only experiments the $\mathrm{RH}$ was less than $9 \%$, the production of $\mathrm{OH}$ radicals from the photolysis of unreacted ozone should be minimal (Rohrer et al., 2005), confirming that the increase in the $\mathrm{OS}_{C}$ in the $\mathrm{OH}$ radical initiated aging experiments (discussed above) is not due to UV-initiated decomposition of the SOA products, but to $\mathrm{OH}$ radical reactions. This is in line with a recent study where no significant change in the $\mathrm{O} / \mathrm{C}$ ratio was determined by a time-of-flight aerosol mass spectrometer ( $\mathrm{ToF}$ - 


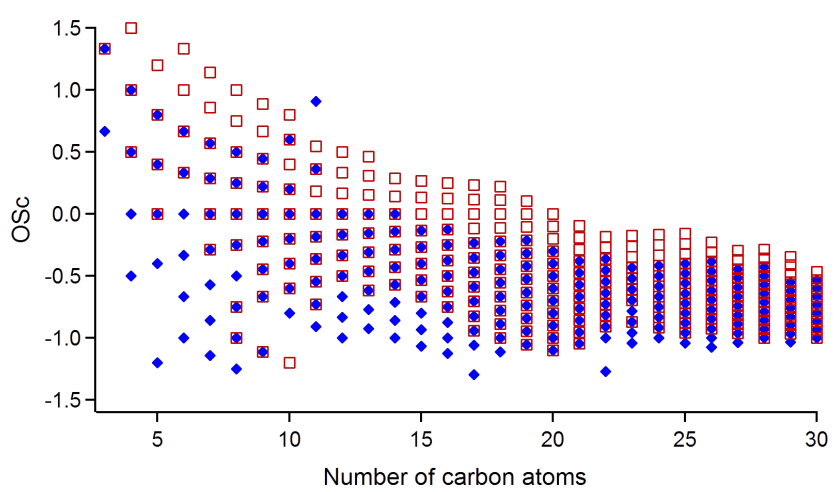

Figure 5. Carbon oxidation state of the molecules in SOA from ozonolysis (blue diamonds) and $\mathrm{OH}$-initiated reaction (red squares) of $\alpha$-pinene.

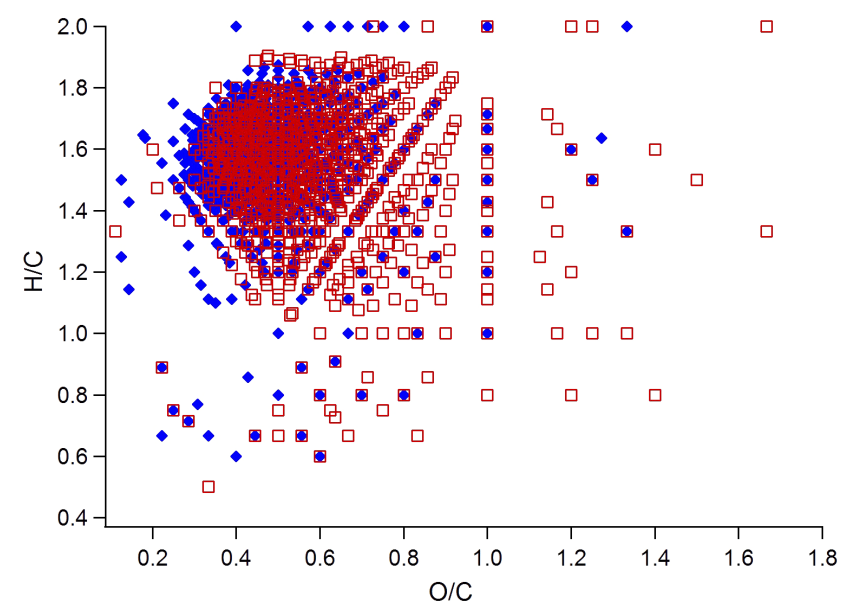

Figure 6. Van Krevelen diagram for molecules in SOA from ozonolysis (blue diamonds) and $\mathrm{OH}$-initiated reaction (red squares) of $\alpha$-pinene.

AMS) when the SOA produced from dark ozonolysis of $\alpha$ pinene was exposed to light representing the solar energy distribution at Earth's surface (Denjean et al., 2015). On the other hand, this is in contrast to findings reported by Wong et al. (2015) who observed photolytic aging of $\alpha$-pinene SOA in the presence of ammonium sulfate that exhibited a dependence on relative humidity.

\subsection{LC/MS results}

Due to competitive ionization of analytes in the ESI direct infusion analysis of the aerosol samples that are known to have a very complex matrix, the ion intensities do not directly reflect the concentration of the molecules in the sample. Therefore, the effect of aging processes on the SOA composition was additionally investigated using LC coupled with HRMS. All data described in this section (except discussion of Figs. S3 and S4) correspond to experiments performed at CESAM chamber. A list of tentatively identified prod- ucts formed during dark ozonolysis of the BVOC mixture is shown in Table S1. The majority of the identified compounds were attributed to $\alpha$ - and $\beta$-pinene oxidation products which can be explained by the fact that both of these precursors contributed to about $60 \%$ of the total BVOC mixture concentration (ppbv) used in this study. On the other hand, none of the chromatographic peaks were associated with isoprene oxidation products which could be due to the relatively low (about $10 \%)$ contribution of isoprene to the total mixture. Moreover, isoprene is known to produce very low aerosol yields (less than 0.01) when reacted with ozone (Kleindienst et al., 2007). Most of the tentatively identified compounds have been previously observed in aerosol samples from laboratory (e.g. Yu et al., 1999; Szmigielski et al., 2007; Glasius et al., 2000; Müller et al., 2008, 2009; Camredon et al., 2010; Gao et al., 2010; Yasmeen et al., 2010; Kourtchev et al., 2014) and field studies (e.g. Gómez-González et al., 2012; Kristensen et al., 2013, 2014; Kourtchev et al., 2013). Therefore, to avoid unnecessary repetition, the sources and processes leading to the formation of these compounds are not discussed here. Although the LC/MS allowed separation and identification of a considerably smaller number of molecules compared to direct infusion analysis, some of them are very useful markers for aerosol source characterization and are good indicators of the processes involved in the formation of the SOA. These include well-known first-generation oxidation products of $\alpha$-pinene such as cis-pinic acid, terpenylic acid and pinonic acid, as well as later generation oxidation products of monoterpenes, i.e. 1,2,3-butanetricarboxylic acid (MBTCA). It has been suggested that MBTCA is a product of the hydroxyl radical initiated oxidation of pinonic acid in the gas phase (Szmigielski et al., 2007; Müller et al., 2012; Yasmeen et al., 2012). Therefore, both pinonic acid and MBTCA could be used to monitor the evolution of $\mathrm{OH}$ radical initiated aging of the SOA.

Compared to the direct infusion analysis, only a very small number of dimers were separated using the LC/MS method in all samples, irrespective of the aging conditions. These dimers include isomers with $\mathrm{m} / \mathrm{z}$ 337.20172, $\mathrm{m} / \mathrm{z}$ 343.13983, $\mathrm{m} / \mathrm{z}$ 357.15509, $\mathrm{m} / z$ 367.17599, $\mathrm{m} / \mathrm{z} 387.20221$ and $\mathrm{m} / \mathrm{z} 369.19141$, consistent with previous studies that applied LC/MS for the analysis of SOA (e.g. Kristensen et al., 2013, 2014). Four of these dimers - pinyl-diaterpenyl ester MW $358(\mathrm{~m} / z$ 357.15509), pinyl-diaterebyl dimer MW $344(\mathrm{~m} / z$ 343.13983), pinonylpinyl dimer MW $368(\mathrm{~m} / z$ 367.17599) and MW 388 dimer ester $(m / z$ 387.20221) - have been identified previously in SOA from ozonolysis of $\alpha$-pinene (e.g. Yasmeen et al., 2010; Kristensen et al., 2013, 2014), while none of them were observed in the SOA from the $\mathrm{OH}$ radical initiated oxidation of $\alpha$-pinene (Kristensen et al., 2014). It must be noted that these dimers were also observed during the direct infusion analysis. Interestingly, the tentative structures of the three dimers reported in the literature (Yasmeen et al., 2010; Kristensen et al., 2013, 2014) contained pinic acid, which is a less impor- 
tant product in the $\mathrm{OH}$ radical initiated oxidation than in the ozonolysis of $\alpha$-pinene (Kristensen et al., 2014). The chromatographic peak areas for all four dimers, determined by LC/MS, showed relatively good linear fit with $R^{2}>0.90$ suggesting that these compounds are possibly formed through similar processes. It should be noted that the observed small number of dimers in the LC/MS chromatogram from $\alpha$ pinene ozonolysis, and their absence in the SOA generated from the $\mathrm{OH}$ radical initiated oxidation of $\alpha$-pinene, in previous studies and the current work, does not necessarily mean that oligomers are not formed in the latter reaction. The lack of chromatographically resolved dimers in the $\mathrm{OH}$ radical initiated SOA could be explained by the selectivity of the utilized LC columns. The integration of chromatographic "humps" eluting at the end of the chromatograms from both ozonolysis and $\mathrm{OH}$ radical initiated reaction of $\alpha$ pinene (Figs. S3 and S4) reveals the presence of a large number of dimers, trimers and tetramers that were not resolved by the LC column. The overall oligomer distribution of these unresolved LC "humps" resembles that of the respective direct infusion mass spectra.

Figure 7 shows concentrations of selected first- and latergeneration oxidation products, as well as dimers in the SOA produced under different aging conditions. Irrespective of the aging conditions, and even during the dark ozonolysis experiments (without addition of $\mathrm{OH}$ radicals), all samples contained MBTCA, the $\mathrm{OH}$ radical initiated oxidation product of $\alpha$-pinene. It has been estimated that the ozonolysis of $\alpha$ pinene results in the formation of $\mathrm{OH}$ radicals with a yield between 0.8 and 1.0 (Atkinson et al., 1997; Presto and Donahue, 2004). Therefore, without the use of an $\mathrm{OH}$ radical scavenger, a substantial fraction of $\alpha$-pinene and other terpenes present in the mixture can be oxidized by $\mathrm{OH}$ radicals (Henry and Donahue, 2011). During the dark aging experiments (with SOA exposure to residual ozone), the concentrations of the marker compounds remained unchanged even after $9 \mathrm{~h}$ of SOA exposure, indicating that all $\mathrm{OH}$ radicals produced from the BVOC ozonolysis were immediately consumed in the first hour of the reaction (Fig. 7a). The concentrations of the first-generation products and the dimers did not change during the dark aging experiments either. In contrast, the concentration of MBTCA increased when $\mathrm{OH}$ radicals were introduced into the system (Fig. 7b) followed by a decrease in the concentration of pinonic acid and pinic acid, confirming that pinonic acid is further oxidized into MBTCA (Müller et al., 2008).

In the UV-only aging experiments the concentrations of all marker compounds in the SOA remained unaffected suggesting that the observed changes in the photolysis experiments with $\mathrm{OH}$ radicals (discussed above) are due to the $\mathrm{OH}$ radical initiated chemistry rather than photolytic degradation of the first-generation products. Irrespective of the tested conditions, the contribution of the dimers to the SOA mass showed no statistical difference (Table S2) indicating that none of the
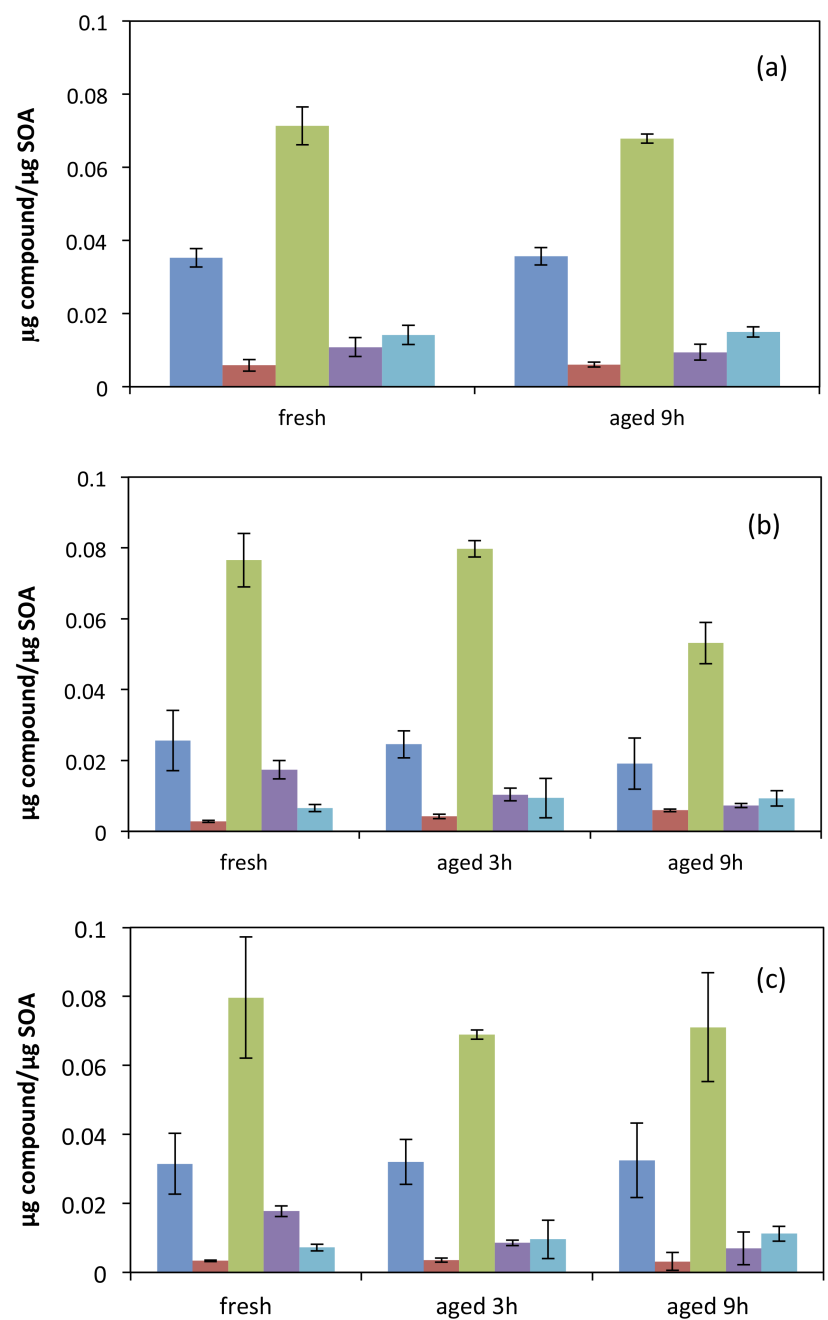

Figure 7. Normalized concentrations ( $\mu \mathrm{g} \mu \mathrm{g}^{-1} \mathrm{SOA}$ ) of terpenylic acid (dark blue), MBTCA (red), pinic acid (light green), pinonic acid (violet), and a dimer MW 358 (light blue) at three aging conditions: (a) dark aging with exposure to residual ozone, (b) $\mathrm{OH}$ radical initiated aging and (c) UV-only aging experiments. Pinic, pinonic and terpenylic acids represent organic species associated with fresh SOA, whereas MBTCA is associated with aged SOA. The peak areas for all four dimers, determined by LC/MS, showed relatively good linear fit with $R^{2}>0.90$ suggesting that these compounds are formed through similar processes. To avoid overloading the figure, only one, the most commonly observed dimer with MW 358 in both ambient and laboratory-generated OA, is shown in the figure.

studied conditions have an effect on dimer decomposition or formation.

\section{Conclusions}

In this study the influence of several aging processes on the molecular composition of organic aerosols has been investigated using direct infusion and liquid chromatography HRMS. SOA formed from ozonolysis of a BVOC mixture 
was aged for 8-9 $\mathrm{h}$ in the dark with residual ozone, under UV irradiation, and by $\mathrm{OH}$ radicals formed from the continuous photolysis of $\mathrm{H}_{2} \mathrm{O}_{2}$. Dark aging and UV aging in the presence of ozone and UV irradiation closely resembling the solar energy distribution at Earth's surface did not significantly affect the molecular composition of studied SOA. In contrast, $\mathrm{OH}$ radical initiated aging showed an increase in $\mathrm{OS}_{\mathrm{C}}$ and elemental O / $\mathrm{C}$ ratios of the BSOA components from the studied BVOC mixture. None of the aging processes produced an observable effect on the oligomers formed from the ozonolysis of the BVOC mixture and they were found to be equally abundant in both "fresh" and "aged SOA". Additional separate dark ozonolysis and $\mathrm{OH}$-initiated experiments with $\alpha$ pinene (a major component of the studied mixture) showed that oligomers are an important group of compounds in both oxidation schemes. However, oligomers in the $\mathrm{OH}$-initiated SOA were shifted towards higher masses and were not readily resolved by the LC techniques applied here, indicating that their importance could have been underestimated in previous similar studies. SOA from the $\mathrm{OH}$ - initiated oxidation of $\alpha$-pinene had a significantly higher $\mathrm{OS}_{\mathrm{C}}$ and $\mathrm{O} / \mathrm{C}$ compared to that from pure ozonolysis experiments, confirming that the $\mathrm{OH}$ radical reaction is more likely to be responsible for the occurrence of highly oxidized species in ambient biogenic SOA. Considering that the timescale ( $8-9 \mathrm{~h})$ of the aging reaction in our experiments was still substantially lower than the lifetime of organic aerosol in the real atmosphere (up to 12 days) (Robinson et al., 2007; Rudich et al., 2007), the observed $\mathrm{OH}$ aging effects could be substantially stronger when SOA is aged over a longer period in the ambient atmosphere.

\section{The Supplement related to this article is available online at doi:10.5194/acp-15-5683-2015-supplement.}

\begin{abstract}
Acknowledgements. Research at the University of Cambridge was supported by a M. Curie Intra-European fellowship (project no. 254319) and the European Research Council (ERC starting grant 279405). The work at LISA and University College Cork was funded by the European Commission (project EUROCHAMP-2, contract no. 228335). Researchers in Cork acknowledge funding from Science Foundation Ireland (11/RFP/GEO3200). Authors would like to thank Olalekan Popoola at University of Cambridge for helping to improve Mathematica code for mass spectral data evaluation. Aline Gratien, Manuela Cirtog and Ricardo SuarezBertoa are gratefully acknowledged for carrying out overnight aging experiments at the CESAM chamber in the preparatory phase of this work. The MCM/AtChem group at the University of Leeds is gratefully acknowledged for providing access to the Master Chemical Mechanism and the tools required for using it.
\end{abstract}

Edited by: S. A. Nizkorodov

\section{References}

Aaltonen, H., Pumpanen, J., Pihlatie, M., Hakola, H., Helleìn, H., Kulmala, L., Vesala, T., and Bäck, J.: Boreal pine forest floor biogenic volatile organic compound emissions peak in early autumn, Agr. Forest Meteorol., 151, 682-691, 2011.

Atkinson, R., Aschmann, S. M., and Pitts Jr., J. N.: Rate constants for the gas-phase reactions of the $\mathrm{OH}$ radical with a series of monoterpenes at $294 \pm 1 \mathrm{~K}$, Int. J. Chem. Kin., 18, 287-299, 1986.

Atkinson, R., Hasegawa, D., and Aschmann, S. M.: Rate constants for the gas-phase reactions of $\mathrm{O}_{3}$ with a series of monoterpenes and related compounds at $296 \pm 2 \mathrm{~K}$, Int. J. Chem. Kinet., 22, 871-887, 1990.

Atkinson, R., Baulch, D. L., Cox, R. A., Hampson, R. F., Kerr, J. A., Rossi, M. J., and Troe, J.: Evaluated kinetic and photochemical data for atmospheric chemistry: supplement VI-IUPAC subcommittee on gas kinetic data evaluation for atmospheric chemistry, J. Phys. Chem. Ref. Data, 26, 1329-1499, 1997.

Bäck, J., Aalto, J., Henriksson, M., Hakola, H., He, Q., and Boy, M.: Chemodiversity of a Scots pine stand and implications for terpene air concentrations, Biogeosciences, 9, 689-702, doi:10.5194/bg-9-689-2012, 2012.

Bateman, A. P., Walser, M. L., Desyaterik, Y., Laskin, J., Laskin, A., and Nizkorodov, S. A.: The effect of solvent on the analysis of secondary organic aerosol using electrospray ionization mass spectrometry, Environ. Sci. Technol., 42, 7341-7346, 2008.

Camredon, M., Hamilton, J. F., Alam, M. S., Wyche, K. P., Carr, T., White, I. R., Monks, P. S., Rickard, A. R., and Bloss, W. J.: Distribution of gaseous and particulate organic composition during dark $\alpha$-pinene ozonolysis, Atmos. Chem. Phys., 10, 2893-2917, doi:10.5194/acp-10-2893-2010, 2010.

Carter,W. P. L., Cocker, D. R., Fitz, D. R., Malkina, I. L., Bumiller, K., Sauer, C. G., Pisano, J. T., Bufalino, C., and Song, C.: A new environmental chamber for evaluation of gas-phase chemical mechanisms and secondary aerosol formation, Atmos. Environ., 39, 7768-7788, 2005.

Chen, Q., Farmer, D. K., Schneider, J., Zorn, S. R., Heald, C. L., Karl, T. G., Guenther, A., Allan, J. D., Robinson, N., Coe, H., Kimmel, J. R., Pauliquevis, T., Borrmann, S., Pöschl, U., Andreae, M. O., Artaxo, P., Jimenez, J. L., and Martin, S. T.: Mass spectral characterization of submicron biogenic organic particles in the Amazon Basin, Geophys. Res. Lett., 36, L20806, doi:10.1029/2009GL039880, 2009

Denjean, C., Formenti, P., Picquet-Varrault, B., Camredon, M., Pangui, E., Zapf, P., Katrib, Y., Giorio, C., Tapparo, A., TemimeRoussel, B., Monod, A., Aumont, B., and Doussin, J. F.: Aging of secondary organic aerosol generated from the ozonolysis of $\alpha$-pinene: effects of ozone, light and temperature, Atmos. Chem. Phys., 15, 883-897, doi:10.5194/acp-15-883-2015, 2015.

Donahue, N. M., Henry, K. M., Mentel, T. F., Kiendler-Scharr, A., Spindler, C., Bohn, B., Brauers, T., Dorn, H. P., Fuchs, H., Tillmann, R., Wahner, A., Saathoff, H., Naumann, K.-H., Mohler, O., Leisner, T., Müller, L., Reinnig, M.-C., Hoffmann, T., Salo, K., Hallquist, M., Frosch, M., Bilde, M., Tritscher, T., Barmet, P., Praplan, A. P., DeCarlo, P. F., Dommen, J., Prevot, A. S. H., and Baltensperger, U.: Aging of biogenic secondary organic aerosol via gas-phase $\mathrm{OH}$ radical reactions, P. Natl. Acad. Sci., 109, 13503-13508, 2012. 
Eddingsaas, N. C., Loza, C. L., Yee, L. D., Chan, M., Schilling, K. A., Chhabra, P. S., Seinfeld, J. H., and Wennberg, P. O.: $\alpha$-pinene photooxidation under controlled chemical conditions - Part 2: SOA yield and composition in low- and high- $\mathrm{NO}_{x}$ environments, Atmos. Chem. Phys., 12, 7413-7427, doi:10.5194/acp-12-74132012, 2012.

Emanuelsson, E. U., Hallquist, M., Kristensen, K., Glasius, M., Bohn, B., Fuchs, H., Kammer, B., Kiendler-Scharr, A., Nehr, S., Rubach, F., Tillmann, R., Wahner, A., Wu, H.-C., and Mentel, Th. F.: Formation of anthropogenic secondary organic aerosol (SOA) and its influence on biogenic SOA properties, Atmos. Chem. Phys., 13, 2837-2855, doi:10.5194/acp-13-2837-2013, 2013.

Epstein, S. A., Blair, S. L., and Nizkorodov, S. A.: Direct photolysis of $\alpha$-pinene ozonolysis secondary organic aerosol: effect on particle mass and peroxide content, Environ. Sci. Technol. 48, $11251-11258,2014$

Flores, J. M., Zhao, D. F., Segev, L., Schlag, P., Kiendler-Scharr, A., Fuchs, H., Watne, Å. K., Bluvshtein, N., Mentel, Th. F., Hallquist, M., and Rudich, Y.: Evolution of the complex refractive index in the UV spectral region in ageing secondary organic aerosol, Atmos. Chem. Phys., 14, 5793-5806, doi:10.5194/acp14-5793-2014, 2014.

Gao, Y., Hall, W. A., and Johnston, M. V.: Molecular composition of monoterpene secondary organic aerosol at low mass loading, Environ. Sci. Technol., 44, 7897-7902, 2010.

Glasius, M., Lahaniati, M., Calogirou, A., Di Bella, D., Jensen, N. R., Hjorth, J., Kotzias, D., and Larsen, B. R.: Carboxylic acids in secondary aerosols from the oxidation of cyclic monoterpenes by ozone, Environ. Sci. Technol., 34, 1001-1010, 2000.

Gómez-González, Y., Wang, W., Vermeylen, R., Chi, X., Neirynck, J., Janssens, I. A., Maenhaut, W., and Claeys, M.: Chemical characterisation of atmospheric aerosols during a 2007 summer field campaign at Brasschaat, Belgium: sources and source processes of biogenic secondary organic aerosol, Atmos. Chem. Phys., 12, 125-138, doi:10.5194/acp-12-125-2012, 2012.

Hakola, H., Tarvainen, V., Laurila, T., Hiltunen, V., Hellen, H., and Keronen, P.: Seasonal variation of VOC concentrations above a boreal coniferous forest, Atmos. Environ., 37, 1623-1634, 2003.

Hall, W. A. and Johnston, M. V.: Oligomer content of alpha-pinene secondary organic aerosol, Aerosol Sci. Technol., 45, 37-45, 2011.

Hallquist, M., Wenger, J. C., Baltensperger, U., Rudich, Y., Simpson, D., Claeys, M., Dommen, J., Donahue, N. M., George, C., Goldstein, A. H., Hamilton, J. F., Herrmann, H., Hoffmann, T., Iinuma, Y., Jang, M., Jenkin, M. E., Jimenez, J. L., Kiendler-Scharr, A., Maenhaut, W., McFiggans, G., Mentel, Th. F., Monod, A., Prévôt, A. S. H., Seinfeld, J. H., Surratt, J. D., Szmigielski, R., and Wildt, J.: The formation, properties and impact of secondary organic aerosol: current and emerging issues, Atmos. Chem. Phys., 9, 5155-5236, doi:10.5194/acp-9-51552009, 2009.

Healy, R. M., Chen, Y., Kourtchev, I., Kalberer, M., O'Shea, D., and Wenger, J. C.: Rapid formation of secondary organic aerosol from the photolysis of 1-nitronaphthalene: role of naphthoxy radical self-reaction, Environ. Sci. Technol., 46, 11813-11820, 2012.

Henry, K. M. and Donahue, N. M.: Effect of the OH radical scavenger hydrogen peroxide on secondary organic aerosol formation from $\alpha$-pinene ozonolysis, Aerosol Sci. Technol., 45, 696-700, 2011.

Henry, K. M. and Donahue, N. M.: Photochemical aging of $\alpha$ pinene secondary organic aerosol: effects of $\mathrm{OH}$ radical sources and photolysis, J. Phys. Chem. A, 116, 5932-5940, 2012.

Jenkin, M. E., Saunders, S. M., and Pilling M. J.: The tropospheric degradation of volatile organic compounds: a protocol for mechanism development, Atmos. Environ., 31, 81-104, 1997.

Jenkin, M. E., Young, J. C., and Rickard, A. R.: The MCM v3.3 degradation scheme for isoprene, Atmos. Chem. Phys. Discuss., 15, 9709-9766, doi:10.5194/acpd-15-9709-2015, 2015.

Jimenez, J. L., Canagaratna, M. R., Donahue, N. M., Prevot, A. S. H., Zhang, Q., Kroll, J. H., DeCarlo, P. F., Allan, J. D., Coe, H., Ng, N. L., Aiken, A. C., Docherty, K. S., Ulbrich, I. M., Grieshop, A. P., Robinson, A. L., Duplissy, J., Smith, J. D., Wilson, K. R., Lanz, V. A., Hueglin, C., Sun, Y. L., Tian, J., Laaksonen, A., Raatikainen, T., Rautiainen, J., Vaattovaara, P., Ehn, M., Kulmala, M., Tomlinson, J. M., Collins, D. R., Cubison, M. J., Dunlea, E. J., Huffman, J. A., Onasch, T. B., Alfarra, M. R., Williams, P. I., Bower, K., Kondo, Y., Schneider, J., Drewnick, F., Borrmann, S., Weimer, S., Demerjian, K., Salcedo, D., Cottrell, L., Griffin, R., Takami, A., Miyoshi, T., Hatakeyama, S., Shimono, A., Sun, J. Y., Zhang, Y. M., Dzepina, K., Kimmel, J. R., Sueper, D., Jayne, J. T., Herndon, S. C., Trimborn, A. M., Williams, L. R., Wood, E. C., Middlebrook, A. M., Kolb, C. E., Baltensperger, U., and Worsnop, D. R.: Evolution of organic aerosols in the atmosphere, Science, 326, 1525-1529, 2009.

Kalberer, M., Paulsen, D., Sax, M., Steinbacher, M., Dommen, J., Prevot, A. S. H., Fisseha, R., Weingartner, E., Frankevich, V., Zenobi, R., and Baltensperger, U.: Identification of polymers as major components of atmospheric organic aerosols, Science, 303, 1659-1662, 2004.

Kanakidou, M., Seinfeld, J. H., Pandis, S. N., Barnes, I., Dentener, F. J., Facchini, M. C., Van Dingenen, R., Ervens, B., Nenes, A., Nielsen, C. J., Swietlicki, E., Putaud, J. P., Balkanski, Y., Fuzzi, S., Horth, J., Moortgat, G. K., Winterhalter, R., Myhre, C. E. L., Tsigaridis, K., Vignati, E., Stephanou, E. G., and Wilson, J.: Organic aerosol and global climate modelling: a review, Atmos. Chem. Phys., 5, 1053-1123, doi:10.5194/acp-5-1053-2005, 2005.

Kleindienst, T. E., Lewandowski, M., Offenberg, J. H., Jaoui, M., and Edney, E. O.: Ozone-isoprene reaction: Re-examination of the formation of secondary organic aerosol, Geophys. Res. Lett., 34, L01805, doi:10.1029/2006GL027485, 2007.

Kourtchev, I., Fuller, S., Aalto, J., Ruuskanen, T. M., McLeod, M. W., Maenhaut, W., Jones, R., Kulmala, M., and Kalberer, M.: Molecular composition of boreal forest aerosol from Hyytiälä, Finland, using ultrahigh resolution mass spectrometry, Environ. Sci. Technol., 47, 4069-4079, 2013.

Kourtchev, I., Fuller, S. J., Giorio, C., Healy, R. M., Wilson, E., O’Connor, I., Wenger, J. C., McLeod, M., Aalto, J., Ruuskanen, T. M., Maenhaut, W., Jones, R., Venables, D. S., Sodeau, J. R., Kulmala, M., and Kalberer, M.: Molecular composition of biogenic secondary organic aerosols using ultrahigh-resolution mass spectrometry: comparing laboratory and field studies, Atmos. Chem. Phys., 14, 2155-2167, doi:10.5194/acp-14-21552014, 2014.

Kristensen, K., Enggrob, K. L., King, S. M., Worton, D. R., Platt, S. M., Mortensen, R., Rosenoern, T., Surratt, J. D., Bilde, M., Gold- 
stein, A. H., and Glasius, M.: Formation and occurrence of dimer esters of pinene oxidation products in atmospheric aerosols, Atmos. Chem. Phys., 13, 3763-3776, doi:10.5194/acp-13-37632013, 2013.

Kristensen, K., Cui, T., Zhang, H., Gold, A., Glasius, M., and Surratt, J. D.: Dimers in $\alpha$-pinene secondary organic aerosol: effect of hydroxyl radical, ozone, relative humidity and aerosol acidity, Atmos. Chem. Phys., 14, 4201-4218, doi:10.5194/acp-14-42012014, 2014.

Kroll, J. H., Donahue, N. M., Jimenez, J. L., Kessler, S. H., Canagaratna, M. R., Wilson, K. R., Altieri, K. E., Mazzoleni, L. R., Wozniak, A. S., Bluhm, H., Mysak, E. R., Smith, J. D., Kolb, C. E., and Worsnop, D. R.: Carbon oxidation state as a metric for describing the chemistry of atmospheric organic aerosol, Nat. Chem., 3, 133-139, 2011.

Kundu, S., Fisseha, R., Putman, A. L., Rahn, T. A., and Mazzoleni, L. R.: High molecular weight SOA formation during limonene ozonolysis: insights from ultrahigh-resolution FT-ICR mass spectrometry characterization, Atmos. Chem. Phys., 12, 5523-5536, doi:10.5194/acp-12-5523-2012, 2012.

Müller, L., Reinnig, M.-C., Warnke, J., and Hoffmann, Th.: Unambiguous identification of esters as oligomers in secondary organic aerosol formed from cyclohexene and cyclohexene $/ \alpha$ pinene ozonolysis, Atmos. Chem. Phys., 8, 1423-1433, doi:10.5194/acp-8-1423-2008, 2008.

Müller, L., Reinnig, M. C., Hayen, H., and Hoffmann, T.: Characterization of oligomeric compounds in secondary organic aerosol using liquid chromatography coupled to electrospray ionization Fourier transform ion cyclotron resonance mass spectrometry, Rapid Commun. Mass Sp., 23, 971-979, 2009.

Müller, L., Reinnig, M.-C., Naumann, K. H., Saathoff, H., Mentel, T. F., Donahue, N. M., and Hoffmann, T.: Formation of 3-methyl1,2,3-butanetricarboxylic acid via gas phase oxidation of pinonic acid -a mass spectrometric study of SOA aging, Atmos. Chem. Phys., 12, 1483-1496, doi:10.5194/acp-12-1483-2012, 2012.

Nizkorodov, S. A., Laskin, J., and Laskin, A.: Molecular chemistry of organic aerosols through the application of high resolution mass spectrometry, Phys. Chem. Chem. Phys., 13, 3612-3629, 2011.

Presto, A. A. and Donahue, N. M.: Ozonolysis fragment quenching by nitrate formation: the pressure dependence of prompt $\mathrm{OH}$ radical formation, J. Phys. Chem. A, 108, 9096-9104, 2004.

Putman, A. L., Offenberg, J. H., Fisseha, R., Kundu, S., Rahn, T. A., and Mazzoleni, L. R.: Ultrahigh-resolution FT-ICR mass spectrometry characterization of $\alpha$-pinene ozonolysis SOA, Atmos. Environ., 46, 164-172, 2012.

Qi, L., Nakao, S., and Cocker, D. R.: Aging of secondary organic aerosol from $\alpha$-pinene ozonolysis: Roles of hydroxyl and nitrate radicals, J. Air Waste Manag., 62, 1359-1369, 2012.

Reinhardt, A., Emmenegger, C., Gerrits, B., Panse, C., Dommen, J., Baltensperger, U., Zenobi, R., and Kalberer, M.: Ultrahigh mass resolution and accurate mass measurements as a tool to characterize oligomers in secondary organic aerosols, Anal. Chem., 79, 4074-4082, 2007.

Renard, P., Siekmann, F., Salque, G., Demelas, C., Coulomb, B., Vassalo, L., Ravier, S., Temime-Roussel, B., Voisin, D., and Monod, A.: Aqueous-phase oligomerization of methyl vinyl ketone through photooxidation -Part 1: Aging processes of oligomers, Atmos. Chem. Phys., 15, 21-35, doi:10.5194/acp-1521-2015, 2015.

Robinson, A. L., Donahue, N. M., Shrivastava, M. K., Weitkamp, E. A., Sage, A. M., Grieshop, A. P., Lane, T. E., Pierce, J. R., and Pandis, S. N.: Rethinking organic aerosols: Semivolatile emissions and photochemical aging, Science, 315, 1259-1262, 2007.

Rohrer, F., Bohn, B., Brauers, T., Brüning, D., Johnen, F.-J., Wahner, A., and Kleffmann, J.: Characterisation of the photolytic HONO-source in the atmosphere simulation chamber SAPHIR, Atmos. Chem. Phys., 5, 2189-2201, doi:10.5194/acp-5-21892005, 2005.

Romonosky, D. E., Laskin, A., Laskin, J., and Nizkorodov, S. A.: High-resolution mass spectrometry and molecular characterization of aqueous photochemistry products of common types of secondary organic aerosols, J. Phys. Chem. A, 119, 2594-2606, 2015.

Rudich, Y., Donahue, N. M., and Mentel, T. F.: Aging of organic aerosol: Bridging the gap between laboratory and field studies, Annu. Rev. Phys. Chem., 58, 321-352, 2007.

Saunders, S. M., Jenkin, M. E., Derwent, R. G., and Pilling, M. J.: Protocol for the development of the Master Chemical Mechanism, MCM v3 (Part A): tropospheric degradation of nonaromatic volatile organic compounds, Atmos. Chem. Phys., 3, 161-180, doi:10.5194/acp-3-161-2003, 2003.

Shilling, J. E., Chen, Q., King, S. M., Rosenoern, T., Kroll, J. H., Worsnop, D. R., DeCarlo, P. F., Aiken, A. C., Sueper, D., Jimenez, J. L., and Martin, S. T.: Loading-dependent elemental composition of $\alpha$-pinene SOA particles, Atmos. Chem. Phys., 9, 771-782, doi:10.5194/acp-9-771-2009, 2009.

Sleighter, R. L., Chen, H., Wozniak, A. S., Willoughby, A. S., Caricasole, P., and Hatcher, P. G.: Establishing a measure of reproducibility of ultrahigh resolution mass spectra for complex mixtures of natural organic matter, Anal. Chem., 84, 9184-9191, 2012.

Szmigielski, R., Surratt, J. D., Gómez-González, Y., Van der Veken, P., Kourtchev, I., Vermeylen, R., Blockhuys, F., Jaoui, M., Kleindienst, T. E., Lewandowski, M., Offenberg, J. H., Edney, E. O., Seinfeld, J. H., Maenhaut, W., and Claeys, M.: 3methyl-1,2,3- butanetricarboxylic acid: An atmospheric tracer for terpene secondary organic aerosol, Geophys. Res. Lett., 34, L24811, doi:10.1029/2007GL031338, 2007.

Thüner, L. P., Bardini, P., Rea, G. J., and Wenger, J. C.: Kinetics of the gas-phase reactions of $\mathrm{OH}$ and $\mathrm{NO}_{3}$ radicals with dimethylphenols, J. Phys. Chem. A, 108, 11019-11025, 2004.

Tolocka, M. P., Jang, M., Ginter, J., Cox, F., Kamens, R., and Johnston, M.: Formation of Oligomers in Secondary Organic Aerosol, Environ. Sci. Technol., 38, 1428-1434, 2004.

Wang, J., Doussin, J. F., Perrier, S., Perraudin, E., Katrib, Y., Pangui, E., and Picquet-Varrault, B.: Design of a new multi-phase experimental simulation chamber for atmospheric photosmog, aerosol and cloud chemistry research, Atmos. Meas. Tech., 4, 2465-2494, doi:10.5194/amt-4-2465-2011, 2011.

Wong, J. P. S., Zhou, S., and Abbatt, J. P. D.: Changes in secondary organic aerosol composition and mass due to photolysis: relative humidity dependence, J. Phys. Chem. A., 119, 4309-4316, doi:10.1021/jp506898c, 2015.

Wozniak, A. S., Bauer, J. E., Sleighter, R. L., Dickhut, R. M., and Hatcher, P. G.: Technical Note: Molecular characterization of aerosol-derived water soluble organic carbon using ultrahigh res- 
olution electrospray ionization Fourier transform ion cyclotron resonance mass spectrometry, Atmos. Chem. Phys., 8, 50995111, doi:10.5194/acp-8-5099-2008, 2008.

Yasmeen, F., Vermeylen, R., Szmigielski, R., Iinuma, Y., Böge, O., Herrmann, H., Maenhaut, W., and Claeys, M.: Terpenylic acid and related compounds: precursors for dimers in secondary organic aerosol from the ozonolysis of $\alpha$ - and $\beta$-pinene, Atmos. Chem. Phys., 10, 9383-9392, doi:10.5194/acp-10-9383-2010, 2010.

Yasmeen, F., Vermeylen, R., Maurin, N., Perraudin, E., Doussin, J.-F., and Claeys, M.: Characterization of tracers for aging of $\alpha$-pinene secondary organic aerosol using liquid chromatography/negative ion electrospray ionization mass spectrometry, Environ. Chem., 9, 236-246, doi:10.1071/EN11148, 2012.
Yu, J., Cocker III, D. R., Griffin, R. J., Flagan, R. C., and Seinfeld, J. H.: Gas-phase ozone oxidation of monoterpenes: Gaseous and particulate products, J. Atmos. Chem., 34, 207-258, 1999.

Zhao, D. F., Kaminski, M., Schlag, P., Fuchs, H., Acir, I.-H., Bohn, B., Häseler, R., Kiendler-Scharr, A., Rohrer, F., Tillmann, R., Wang, M. J., Wegener, R., Wildt, J., Wahner, A., and Mentel, Th. F.: Secondary organic aerosol formation from hydroxyl radical oxidation and ozonolysis of monoterpenes, Atmos. Chem. Phys., 15, 991-1012, doi:10.5194/acp-15-991-2015, 2015.

Zhou, S., Shiraiwa, M., McWhinney, R., Pöschl, U., and Abbatt, J. P. D.: Kinetic limitations in gas-particle reactions arising from slow diffusion in secondary organic aerosol, Faraday Discuss. 165, 391-406, 2013. 